\title{
The first electronic polytomous key to the world species of the subgenus Typhlodromus (Anthoseius) De Leon (Acari: Phytoseiidae)
}

\author{
FABIO AKASHI HERNANDES ${ }^{1,2}$, SERGE KREITER $^{1} \&$ MARIE-STÉPHANE TIXIER $^{1}$ \\ ${ }^{1}$ Montpellier SupAgro, Unité Mixte de Recherche Centre de Biologie pour la Gestion des Populations (INRA/IRD/CIRAD/ \\ Montpellier SupAgro), Campus International de Baillarguet, CS 30016, 34988 Montferrier-sur-Lez cedex, France \\ ${ }^{2}$ Departamento de Zoologia, Universidade Estadual Paulista, Rio Claro, SP, Brazil 13506-900.
}

\begin{abstract}
This paper describes the first polytomous computerised identification key within the family Phytoseiidae. It applies to the females of the world species of the subgenus Typhlodromus (Anthoseius) De Leon. This group is one of the largest within the family Phytoseiidae and the sub-family Typhlodrominae, with nearly 350 species currently recognised worldwide. No identification tool of these species exists at the world level, which makes their identification very difficult and unsecure. Thirty five characters were used to characterise each of the 343 species. Among these characters, 14 are discrete and 21 are continuous. The polytomous key was constructed using the free software DELTA 1.04 (DEscription Language for TAxonomy) and is freely available at the web site: http://www1.montpellier.inra.fr/CBGP/phytoseiidae/ anthoseiuskeypresentation.html. We hope that this work will open new perspectives for the identification of species of other genera (especially the largest ones, e.g. Neoseiulus, Euseius, Amblyseius) which contains more than 150 species and for which no key presently exists. We also expect that the present work will make the identification of the world species of Typhlodromus (Anthoseius) easier and more secure. Finally, we expect a contribution from the whole Phytoseiidae scientist community to improve subsequent versions of the key.
\end{abstract}

Key words: Taxonomy, identification, Acari, predators

\section{Introduction}

Phytoseiidae Berlese (Acari: Mesostigmata) is a mite family that contains predatory species useful to control important insect and mite pests of cultivated plants worldwide (McMurtry \& Croft 1997; Gerson et al. 2003). The correct identification of species of Phytoseiidae is thus of huge interest for biological control success. Species diagnostic is mainly based on morphological characters of females. Despite recent progresses in molecular systematics (Jeyaprakash \& Hoy 2002; Tixier et al. 2006a, b, 2010, 2011, 2012; Okassa et al. 2009, 2010; Kanouh et al. 2010a, b), most species continue to be circumscribed based solely on morphology, since morphological data are often the only sort of information available. To facilitate Phytoseiidae diagnostics, identification keys have been developed. However, most of them are restricted to few genera and often apply to a single country or region and all follow the model of traditional dichotomous keys. Lastly, they rapidly become obsolete as new species are described and the keys not updated. These dichotomous keys are relatively simple and portable, but they oblige the user to follow a predetermined path in recognising characters or character states (Norton 2002, Hardwick 2010). Furthermore, if a critical character is obscured, damaged or missing at any step along the key pathway, the choice required by the couplet is unanswerable and the identification impossible. To overcome these problems, World Wide Web and computerisation tools have opened new opportunities, especially for more friendly and efficient identification tools. The so-called polytomous keys (matrix based) allow the user to select from characters which are more easily recognised, in any desired order (Lobanov 2003; Watson et al. 2003; Walter \& Winterton 2007; Hardwick 2010). This means that users can by-pass characters that are unrecognisable, hidden, damaged or missing.

Here we describe the development of a computerised polytomous key to identify females of the world species of the subgenus Typhlodromus (Anthoseius) De Leon. This subgenus is one of the largest within the family Phytoseiidae, and the largest within the sub-family Typhlodrominae, currently comprising nearly 350 valid species (Moraes et al. 1986; 2004; Chant \& McMurtry 2007). Despite efforts to build regional keys (Ueckermann \& Loots 